\title{
Multiscale effect of thermomechanical loads on the NbC-Steel microstructure obtained by SPS
}

\author{
Vanessa Seriacopi ${ }^{1}$, Ana Julia de Oliveira Tertuliano ${ }^{1}$, Guido Boidi ${ }^{1}$, Ivan García Fornaris ${ }^{1}$, \\ Izabel Fernanda Machado ${ }^{1}$ \\ ${ }^{1}$ Polytechnic School of the University of São Paulo, Department of Mechatronics and \\ Mechanical Systems Engineering, Brazil, machadoi@usp.br
}

\begin{abstract}
The ABAQUS ${ }^{\circledR}$ commercial software was used to simulate by Finite Element Method (FEM) the stress and the strain fields due to the thermal and mechanical loads applied in the tool microstructure throughout hot forging operations. Therefore, the macroscale (loads applied in the tool) was adapted to the microscale (stress and strain developed in the microstructural features). Materials analyzed in this study, which are prospective to be used as tools, consisted of NbC and tool steel powders, which were mixed, and consolidated by SPS technique (Spark Plasma Sintering). NbC-Steel microstructure was firstly characterized by SEM and, thus it was meshed by OOF $2^{\circledR}$ software (NIST). Subsequently, the microstructural characterization allowed to undergo evaluation of different aspects and critical stress and strain regions, which can favored microstructural damage in the tool material.
\end{abstract}

Keywords: Multiscale effects. Thermomechanical loads. SPS. FEM. NbC-Steel.

\section{Introduction}

Hard materials can be used as tools in many applications. Cemented carbides, for instance, can be applied in thermomechanical processing as well as in machining. Other hard materials are also prospective to be used as tools such as $\mathrm{NbC}$. These hard materials are usually manufactured by powder metallurgy and, the Spark Plasma Sintering (SPS) is a potential process to manufacture hard materials, since there is no pronounced grain growth occurrence and, the consolidation is improved due to the use of pressure during the sintering process [1]. It is worth mentioning, materials for tools have to be wear, thermal and mechanical fatigue resistant [1]. The thermomechanical behavior and, the effect of thermomechanical loads can be conducted by numerical simulation (Finite Element Method - FEM), which enables macro and microanalysis of the material [2]. Therefore, regarding the manufacturing of tools by SPS and the FEM simulation, this work aims: (i-) to manufacture two different samples with different volume fractions of NbC and the S290 tool steel by SPS. The S290 steel was mainly used as a binder and to increase the toughness; and, (ii-) to simulate by FEM the effects of the imposed thermal and mechanical loads on stress and strain fields in the microstructure of these materials.

\section{Materials and Experimental Procedure}

\subsection{Materials}

In this work, the $\mathrm{NbC}$ and S290 tool steel workpieces were consolidated by SPS. The chemical composition of S290 steel powder was: $2.0 \mathrm{C}$; 0.5 Si; $0.3 \mathrm{Mn} ; 3.8 \mathrm{Cr} ; 2.4 \mathrm{Mo}$; $5.1 \mathrm{~V} ; 14.3 \mathrm{~W} ; 11.0 \mathrm{Co}$; and $60.6 \mathrm{Fe}$ (\%wt.). Two different volume fractions of $\mathrm{NbC}$ and $\mathrm{S} 290$ steel samples were evaluated: $88 \% \mathrm{NbC}-12 \% \mathrm{~S} 290$ steel and $52 \% \mathrm{NbC}-48 \% \mathrm{~S} 290 \mathrm{Steel}$. The $\mathrm{NbC}$ powder was supplied by CBMM with particle size $<10 \mu \mathrm{m}$, and the S290 tool steel powder was supplied by BöhlerUddeholm do Brasil Ltda (Böhler S290 Microclean) [3] with particle size $<10 \mu \mathrm{m}$. These powders were used and they were put together in a ball mill. In terms of numerical simulation, the mechanical and physical properties of NbC [4-6] and S290 tool steel [3] used as inputs are shown in Figure 1b. The elastic modulus and yield stress of the NbC were obtained experimentally by means of instrumented microhardness test (Berkovich indenter and load of $7 \mathrm{mN}$ ). $\mathrm{NbC}$ density corresponds to $7,600 \mathrm{~kg} \mathrm{~m}^{-3}$ and the Poisson ratio is 0.22 . S290 tool steel and AISI 1045 steel densities corresponds to 8,300 $\mathrm{kg} \mathrm{m}^{-3}$ and 7,800 $\mathrm{kg} \mathrm{m}^{-3}$, respectively, and the both Poisson ratio of steels is considered 0.30. [3 and 7]. 


\subsection{Experimental and Numerical Procedure}

SPS (experimental procedure) - Samples consolidation: Samples of NbC/S290 steel mixtures were consolidated by SPS process (DR SINTER ${ }^{\circledR}$ SPS 1050 , Syntex Inc) at $1050^{\circ} \mathrm{C}$. The holding time was 5 min and pressure applied throughout the processing was $50 \mathrm{MPa}$. The heating rate used was $100{ }^{\circ} \mathrm{C} / \mathrm{min}$ in the first $10 \mathrm{~min}$ of the consolidation and, of about $20^{\circ} \mathrm{C} / \mathrm{min}$ in the range of temperatures from 900 to $1050{ }^{\circ} \mathrm{C}$. This procedure was important to avoid liquid phase formation during the heating, since the particle size of steel was similar to $\mathrm{NbC} \mathrm{[1].} \mathrm{The} \mathrm{two} \mathrm{samples} \mathrm{were} \mathrm{placed} \mathrm{in} \mathrm{the} \mathrm{same} \mathrm{die,} \mathrm{but} \mathrm{separated} \mathrm{by}$ a graphite disc, so that the samples microstructure could be compared in the same conditions of processing. The consolidation of the sample was evaluated by density measure by means of Archimedes's method.

Thermomechanical loads and boundary conditions - Some considerations were made regarding the simulation of the effect of thermomechanical loads applied in the hot forging tool, in the microstructure of the materials manufactured by SPS. Therefore, the multiscale treatment can be conducted by transposition of the macroscopic stresses to microstructural and nodal mechanical and thermal loads. First of all, an important aspect to point out is the resulting mechanical loads were distributed macroscopically in a circular area with $20 \mathrm{~mm}$ of diameter (tool material). However, these mechanical loads in the 2D FEM simulation were adapted in a rectangular tool-workpiece contact area $\left(50 \mathrm{x} 1 \mu \mathrm{m}^{2}\right)$, in which $50 \mu \mathrm{m}$ in the $\mathrm{x}$-axis (length) and, $1 \mu \mathrm{m}$ corresponds to the thickness of the microstructure in the simulation. Therefore, the microstructural analysis was limited to a rectangular area of $50 \times 35 \mu \mathrm{m}^{2}$ (length (x-axis) x width (y-axis), see Figure 1a) with plane strain considerations. The loads were applied during forging, thus, the properties and main characteristics of the forged material (workpiece) have to be considered. The workpiece area was limited in $50 \times 5 \mu \mathrm{m}^{2}$ with $1 \mu \mathrm{m}$ of thickness. The material selected to be simulated as the workpiece was the AISI 1045 steel. The yield strength of the AISI 1045, in the range of temperatures evaluated, is $553 \mathrm{MPa}$, since it is necessary to determine the nodal forces [8]. The other boundary conditions are: symmetry on the left side (tool and workpiece) and, the constraint in the y-axis direction on the workpiece in order to avoid translational displacement. Contact conditions between the tool and the workpiece are: friction coefficient considered is 0.3 and, thermal conductance is $2000 \mathrm{Wm}^{-2}{ }^{\circ} \mathrm{C}^{-1}$ [8]. The thermal cycle simulated is also displayed in Figure 1a. Thermal loads in the microstructure are related to the temperature difference between the tool and the workpiece during the forging. The contact between the tool (body) at $150^{\circ} \mathrm{C}$ and the workpiece of AISI 1045 steel (counter body) at $1100^{\circ} \mathrm{C}$ lead to an increase in the surface temperature of the tool up to $400{ }^{\circ} \mathrm{C}$ in 5 seconds. After the separation between the tool and the workpiece, a cooling from $400{ }^{\circ} \mathrm{C}$ to $150{ }^{\circ} \mathrm{C}$ also occurred in 5 seconds and before the starting of the next cycle, temperature of the tool remained at $150{ }^{\circ} \mathrm{C}$ for $45 \mathrm{~s}$, as depcits Figure 1a. The heat flux occurred from the bottom to the top direction of the microstructure (y-axis). The parameters and conditions established to carry out this simulation were obtained from [9].

Numerical procedure - Stress and strain fields related to thermal and mechanical loads were calculated by the Abaqus ${ }^{\circledR}$ software in the Standard module. Numerical simulation was developed by FEM applications with Coupled temp-displacement step which allows the coupled thermomechanical analysis. Some simplifications were made in the numerical model presented. The segmentation of the microstructural features was conducted through gray shapes scale. Shortly after this segmentation, the two meshes were created through the software "OOF2", developed at the National Institute of Standards and Technology (NIST) [10] to allow analyzing the effect of second phase particles (S290 tool steel) on the NbC matrix. The meshes were separated into three groups of elements: $\mathrm{NbC}$; S290 steel; and pores. Moreover, in order to increase the accuracy of calculations in terms of stress concentration, the interfaces were refined in the meshes (adaptive mesh refinement). A total of 114,286 plane strain elements were discretized in the mesh of the $48 \%$ S290+NbC (Figure 2).

\section{Results and discussion}

\subsection{SPS consolidation and mesh definition}

Density of the two samples (NbC- tool steel) obtained by SPS was evaluated. The workpiece with $88 \%$ volume fraction of $\mathrm{NbC}$ reached only $61 \%$ of relative density. The best result was found in the sample $52 \%$ of $\mathrm{NbC}$, in which the relative density was $84 \%$. The $\mathrm{NbC}$ has a high melting point and, the sintering was carried out at low temperature $\left(1050{ }^{\circ} \mathrm{C}\right) . \mathrm{Hence}$, the higher steels contents made it possible an improvement in the consolidation, since it has a lower melting point and should have led to a full wet of the particles of $\mathrm{NbC}$. Consequently, the higher density sample was selected to be simulated by FEM. FEM simulations were conducted on the microstructure. Thus, the materials were characterized by scanning electron microscopy (SEM) (JSM 6010LA - Jeol) after consolidation by SPS. The backscattered images were obtained and semi quantitative chemical analysis was carried out by Energy-dispersive X-ray spectroscopy (EDS), so that the different phases could be identified. Figure 2 a shows the $52 \% \mathrm{NbC}-$ Steel microstructure in three shades of gray: (1) NbC is the lightest; (2) S290 steel is the intermediate gray shade; and, (3) pores are in the darkest gray shade (almost black). The image obtained by SEM was adapted to characterize the microstructural features. Figure $2 b$ shows the mesh designed on the microstructure for numerical simulation. 
(a-)

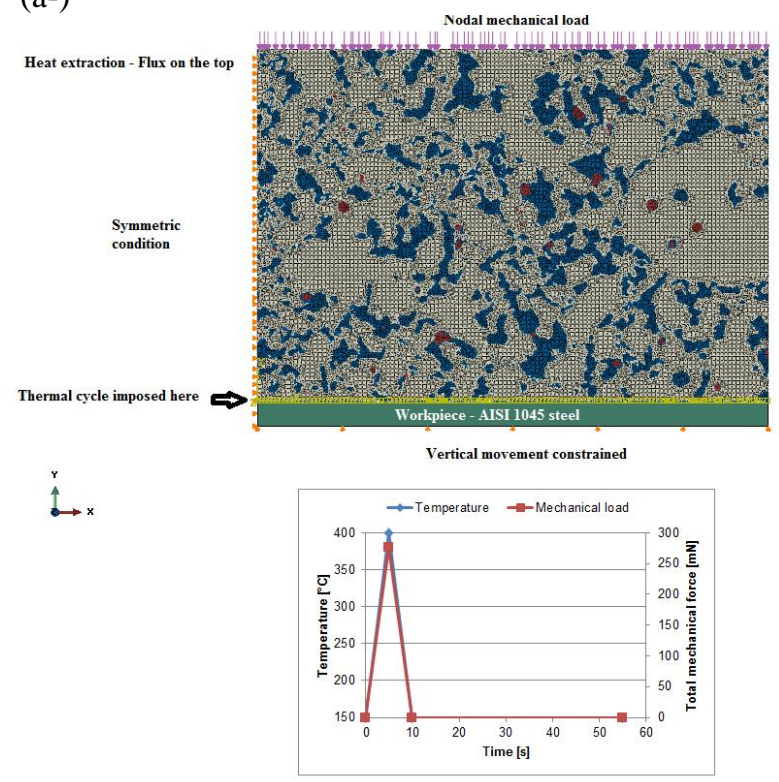

(b-)

\begin{tabular}{|c|c|c|c|c|c|c|}
\hline Material & $\begin{array}{l}\text { Temperature } \\
\left({ }^{\circ} \mathrm{C}\right)\end{array}$ & $\begin{array}{l}\text { Elastic } \\
\text { modulus } \\
(G P a)\end{array}$ & $\begin{array}{l}\text { Yield } \\
\text { stress* } \\
(M P a)\end{array}$ & $\begin{array}{l}\text { Thermal } \\
\text { conductivity } \\
\left(W m^{-1 o} C^{-1}\right)\end{array}$ & $\begin{array}{l}\text { Thermal } \\
\text { expansion } \\
\text { coefficient } \\
\left({ }^{o} C^{-1}\right)\end{array}$ & $\begin{array}{l}\text { Specific } \\
\text { heat } \\
\left(\mathrm{Jkg}^{-1 o} \mathrm{C}^{-1}\right)\end{array}$ \\
\hline \multirow[t]{3}{*}{$\mathrm{NbC}$} & 20 & 371.14 & 5,890 & 14.2 & $6.60 \mathrm{E}-06$ & 250 \\
\hline & 127 & - & - & 16.7 & - & 320 \\
\hline & 500 & 342.88 & - & 23.3 & - & 466 \\
\hline S290 & 20 & 242.00 & 1,155 & 19.0 & - & 410 \\
\hline \multirow[t]{7}{*}{ steel } & 100 & - & - & - & $9.60 \mathrm{E}-006$ & - \\
\hline & 200 & - & - & - & $1.00 \mathrm{E}-005$ & - \\
\hline & 300 & - & - & - & $1.03 \mathrm{E}-005$ & - \\
\hline & 400 & - & - & - & $1.06 \mathrm{E}-005$ & - \\
\hline & 500 & - & - & - & $1.09 \mathrm{E}-005$ & - \\
\hline & 600 & - & - & - & $1.12 \mathrm{E}-005$ & - \\
\hline & 700 & - & - & - & $1.16 \mathrm{E}-005$ & - \\
\hline $\begin{array}{l}1045 \\
\text { steel }\end{array}$ & 20 & 200 & $\mathrm{~J}-\mathrm{C}^{*}$ & 55 & - & 374 \\
\hline
\end{tabular}

Figure 1: (a) Schematic of the boundary conditions and loads which were defined for the thermomechanical numerical procedure. (b) Thermal and mechanical properties of the sintered phases (tool material) and the workpiece material used in the numerical model.

$(\mathrm{a}-)$

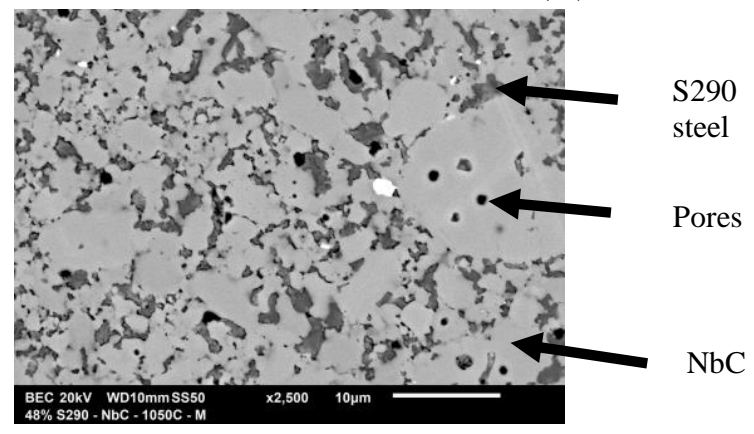

(b-)

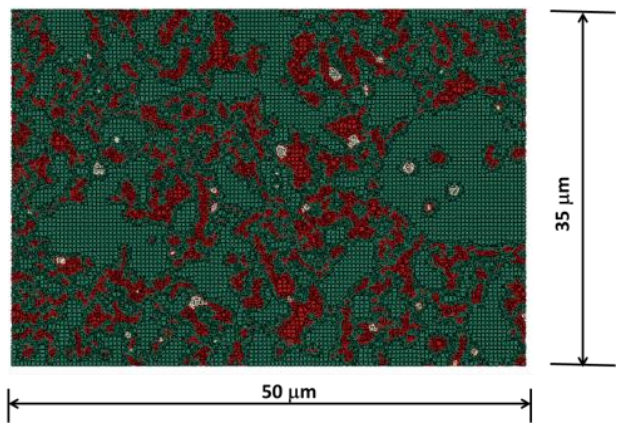

Figure 2: Microstructures of the sample obtained by SPS technique: (a-) NbC $+48 \%$ in volume of S290 tool steel. SEM, back scattered electrons. (b-) Mesh designed on the microstructure.The red regions are ascribed to the S290 steel and, the green regions are consisted of $\mathrm{NbC}$. The white regions are pores contributions.

\subsection{Stress fields}

The thermal and mechanical loads described previously were simulated, and the results of Maximum Principal stress distribution can be observed in Figure 3 in two different steps of the simulation. One is related to the end of the heating up to $400^{\circ} \mathrm{C}$ on the surface, and the other was after cooling, in which temperature remained at $150^{\circ} \mathrm{C}$. The cooling step leads to a process of stress relieving of those generated during the heating. The stresses on niobium carbides (NbC) were higher than the S290 steel and, it can be related to the elastic modulus. However, the NbC matrix remains in the elastic stress conditions, the steel has already started the damage accumulation (deformation) occurring residual stresses effect in this phase. On the other hand, the pores tend to be closed by compressive loads, mainly due to mechanical sources.

\subsection{Strain fields}

According to the results displayed in Figure 4, the tool steel did not expand as $\mathrm{NbC}$ does, since it has a higher thermal expansion coefficient. As a result, higher deformations occur at the interfaces. It is worth mentioning, the interfacial deformations are reduced during the course of post-heating step to post-cooling step. Therefore, the result indicated that the critical stage is the transition between the heating and the cooling, in which damage by means of successive cyclic load applications can occur. Regarding the thermal and mechanical strains, results showed to be consistent with thermal behavior differences, which do not occur between phases, since the thermal conductivities of the two phases (NbC and S290 steel) do not have significant differences at elevated temperatures. 
(a-)

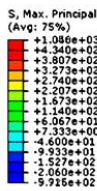

$\stackrel{Y}{i}$
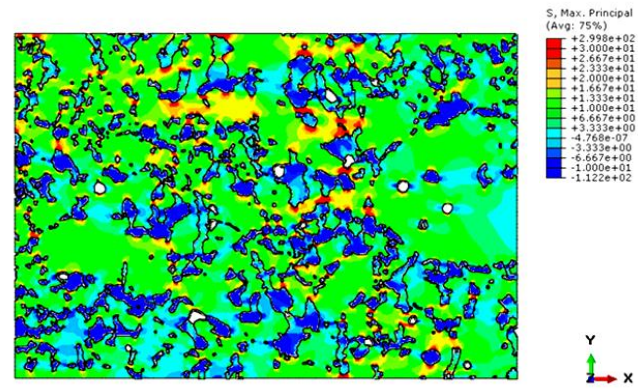

(b-)

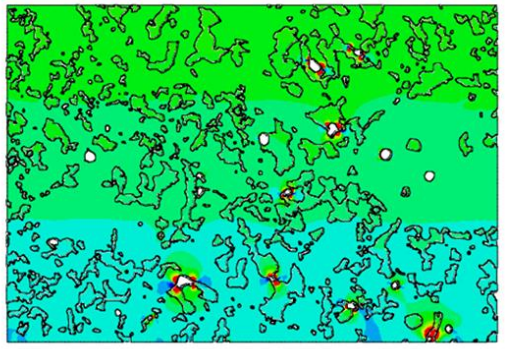

Figure 3: Maximum principal stresses distributions [MPa] on the $48 \% \mathrm{~S} 290$ steel+NbC microstructure, considering the following steps: (a-) post-heating; and, (b-) post-cooling.

(a-)

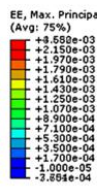

Y.
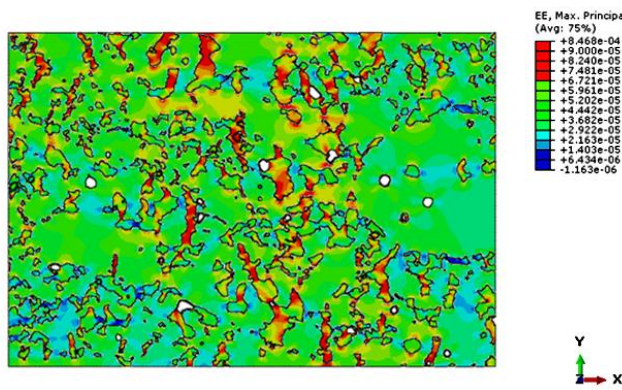

(b-)

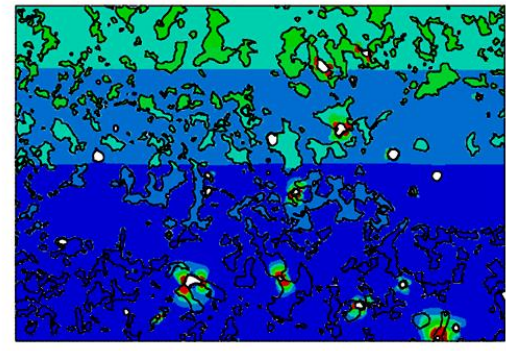

Figure 4: Maximum principal strains distributions on the 48\%S290 steel+NbC microstructure, considering the following steps: (a-) postheating; and (b-) post-cooling. Regarding the temperature, a steady state was established.

\section{Final remarks and Conclusions}

This work aimed to manufacture by the SPS process a prospective material to be used as a tool, in which microstructural features were evaluated taking into account macro and microphenomena involved due to thermomechanical loading simulated by FEM. The results showed higher steel contents provide benefits in the study of behavior of tool during hot forming processes. In the view of the numerical simulation, a thermomechanical load was imposed to evaluate stress and strain fields and relate them to the microstructural features. The work carried out also allows the following conclusions: (i-) the difference between thermal expansion coefficients of the phases results in stress concentrations on the interfaces and also the highest strains were presented in the tool steel; (ii-) the cooling is the critical condition for damage occurrence, because this step leads to a relieving process of stress generated during the heating; and, (iii-) thermal behavior differences do not occur between the phases due to the similar thermal conductivities of them.

\section{Acknowledgements}

The authors acknowledge the National Council for Scientific and Technological Development, CNPq, and the Coordination for the Improvement of Higher Level Personnel, CAPES, for financial support. Additionally, the authors acknowledge the CBMM and Böhler-Uddeholm do Brasil Ltda for supplying NbC and S290 tool steel powders, respectively.

\section{References}

1. R. Orru, R. Licheri, A.M. Locci, A. Cincotti, G. Cao. Consolidation/synthesis of materials by electric current activated/assisted sintering Materials Science and Engineering R 63 (2009) 127-287

2. N.K. Fukumasu, P.L. Pelegrino, G. Cueva, R.M. Souza, A. Sinatora. Numerical analysis of the stresses developed during the sliding of a cylinder over compact graphite iron. Wear. 259 (2005) 1400-1407.

3. Matweb (Material Property), Bohler-Uddeholm BÖHLER S290 MICROCLEAN® High Speed Steel. Further information available at: < http://www.matweb.com/search/DataSheet.aspx?MatGUID=7df03141288648cbb9dad9ad5203619a>. (2014)

4. Hysitron Inc. (Nanomechanics Research Lab.), Sample Analysis Report - Document NRL-D-575. (2013).

5. W.S. Williams, The thermal conductivity of metallic ceramics. JOM. 50 (1998) 62-66.

6. C.K. Jun and P.T.B. Shaffer, Thermal expansion of niobium carbide, hafnium carbide and tantalum carbide at high temperatures. Journal of the Less Common Metals. 24 (1971) 323-327.

7. D.R. Lide, CRC Handbook of chemistry and physics. CRC Press, Boca Raton. FL, $79^{\text {th }}$ ed., 1998.

8. C.Z. Duan, T. Dou, Y.J. Cai, Y.Y. Li. Finite element simulation and experiment of chip formation process during high speed machining of AISI 1045 hardened steel. International Journal of Recent Trends in Engineering. 5 (2009) 46-50.

9. C.R.S. da Silva, M. Boccalini. Thermal cracking of multicomponent white cast iron. Materials Science and Technology. 21 (2005) 565-573.

10. NIST (National Institute of Standards and Technology), OOF: Finite element analysis of microstructures. Further information available at: <http://www.ctcms.nist.gov/oof/oof2/>. (2014). 